\title{
Sterilisation and mentally handicapped people
}

\section{Position Statement}

This Position Statement was prepared by the Section for the Psychiatry of Mental Handicap and approved by Council in March 1988. It is intended as a contribution to the ongoing debate on this issue and does not constitute guidelines for members. The section on sterilisation in "Interim Guidelines on Consent to Medical and Surgical Treatment, Contraception, Sterilisation and Abortion in the Mentally Handicapped" (Bulletin, July 1986, 10, 184-185) no longer applies and all psychiatrists involved in clinical decisions concerning sterilisation of mentally handicapped people are advised to consult their Medical Defence Unions immediately.

\section{Introduction}

Modern concepts of care have increased opportunities for mentally handicapped people to enjoy sexual relationships. They have also increased the risks of exploitation.

Sex education, with the emphasis on personal relationships and responsible sex, should therefore be an ongoing and integral part of training curriculae for all mentally handicapped people.

Advice on and assistance with contraception should be as readily available to all mentally handicapped people as it is to the general population.

\section{Sterilisation}

Sterilisation (tubal tie and vasectomy) should be available as a method of contraception to mentally handicapped people of all ability levels, as it is to the general population.

Mildly - mentally handicapped men and women can, with appropriate guidance and advice, make in- formed decisions about the form of contraception they desire and are able to give valid consent to sterilisation. For this group the existing procedural arrangements are entirely satisfactory and appropriate.

Sterilisation is an acceptable contraceptive method for severely mentally handicapped people who cannot give informed consent under the following circumstances:

the individual concerned is sexually active and there is a risk of pregnancy;

there is sound evidence that the individual is incapable of coping with the emotional and physical stresses of pregnancy or of functioning as a satisfactory parent, even with reasonable support; sterilisation is on medical or social grounds the most appropriate form of contraception.

In such cases adequate safeguards are essential to protect both the patient and the doctor as severely mentally handicapped people are neither able to comprehend the significance of sterilisation nor give valid consent. Currently, no-one is able to give legal consent on their behalf and the present situation which requires high profile Court action is not an acceptable long-term solution.

Special legislation and arrangements are needed. The aim should be to enable decisions to be made speedily, with minimum disruption and distress to patients and their families, on clinical grounds, on the "best interests of the individual" basis. The College recommends that this will be best achieved by the establishment of Special Regional Panels, with a membership including consultant psychiatrists in mental handicap, consultant gynaecologists, consultant surgeons (in the case of men), senior members of the legal profession and lay members, with powers in law to make these decisions, to whom all cases be referred.

\section{Distinction Awards Committee}

The following are College nominated Advisers on Awards in the Regions:

Northern: Dr K. Schapira, Royal Victoria Infirmary, Newcastle upon Tyne; Yorkshire: Professor R. Mindham, University of Leeds; Trent: Professor J. Cooper, Queen's Medical Centre, Nottingham; East Anglia: Dr C. P. B. Brook, Fulbourn Hospital, Cambridge; North West Thames: Professor R. Priest, St Mary's Hospital; North East Thames: Professor T. Silverstone, St Bartholomew's Hospital; South West Thames: Professor A. Crisp, St George's Hospital; South East Thames: Professor J. Watson, Guy's
Hospital, Professor R. Cawley, Institute of Psychiatry; Wessex: Dr B. Barraclough, University Department of Psychiatry, South Hants Hospital; Oxford: Dr E. B. O. Smith, The Radcliffe Hospital, Oxford; South Western: Professor H. G. Morgan, University of Bristol; West Midlands: Professor R. Bluglass, Reaside Clinic, Birmingham; Mersey: Professor J. Copeland, Royal Liverpool Hospital; North Western: Professor D. Goldberg, University of South Manchester; Wales: Dr M. Harper, University of Wales, Cardiff. 